\title{
The pricing of convertible bonds within the Tsiveriotis and Fernandes framework with exogenous credit spread: Empirical analysis
}

\author{
Victor Gushchin* and Erwan Curien \\ *Sophis Technology, 61-62 Fitzwilliam Lane, Dublin 2, Republic of Ireland. \\ Tel: + 353177539 00; Fax: +353 166192 73; E-mail: victor.gushchin@sophis.net
}

Received (in revised form): 20th March 2008

\begin{abstract}
Victor Gushchin has an MS in Mathematics and Applied Mathematics and a PhD in Economics from Moscow State University. He is currently employed as Manager of the Financial Model Validation and QA Front Office teams for Sophis Technology Ireland. In this post, he is also responsible for developing and validating pricing models for convertible bonds and providing assistance to hedge funds in this respect.
\end{abstract}

Erwan Curien was educated in mathematics and physics (Ecole Polytechnique, France, 1998), specialising in finance and statistics (ENSAE, 2001). He is currently employed as the manager of the Quantitative Research team for Sophis Technology France. In this post, he is also responsible for developing models for convertible bonds. He has published several articles on convertible bonds and credit derivatives.

\section{Practical applications}

Owing to its relative simplicity and its ability to incorporate the main characteristics of convertibles that have limited market data, the Tsiveriotis and Fernandes framework is widely used by practitioners for pricing convertible bonds. In our research, we addressed the most important unanswered question regarding the Tsiveriotis and Fernandes framework; does the framework provide accurate and practical valuation consistent with the market? We conducted what we believe is the most extensive empirical research on the subject and found that using a moving-average credit spread results in a valuation that is consistent with the market. The existence of a continuous credit spread that can be used to achieve accurate pricing establishes solid practical grounds for the hedging strategy based on historical implied credit spread that is used by many hedge funds. The co-integration of historical volatility and credit spread described in the article makes it possible, in many cases, to price convertibles without complete market information. Practical advice and examples are provided.

\begin{abstract}
Despite a huge popularity of convertible bonds and a variety of different pricing models, very little empirical research on their valuation has been undertaken. This paper investigates the pricing performance of arguably the most popular among practitioners, the Tsiveriotis
\end{abstract}

and Fernandes approach implemented within a trinomial-tree model with exogenous credit spread using daily market prices on the largest available historical database ( $1500 \mathrm{CBs})$. We demonstrate that using a constant credit spread within that framework would lead to significant mispricing in
Journal of Derivatives $\&$ Hedge Funds, Vol. 14 No. 1, 2008, pp. 50-65 (C) 2008 Palgrave Macmillan Ltd $1753-9641 \$ 30.00$ 
average. By contrast, we present a practical approach for valuing convertible bonds with moving-average credit spread, which leads to acceptable results. We prove that historical volatility and implied credit spread are cointegrated for the majority of bonds in our sample. This allows us to model credit spread based on cointegrated relationship with volatility and extend our model to the cases with limited market information available. The mispricing is proven to be statistically insignificant in the researched convertible bonds. Journal of Derivatives \& Hedge Funds (2008) 14, 50-65. doi:10.1057/jdhf.2008.7

Keywords: convertible bond; credit spread; empirical analysis; Tsiveriotis and Fernandes; cointegration; volatility

\section{INTRODUCTION}

The market for convertible bonds has grown steadily over the past decade. In 2002 there were approximately $\$ 270$ billion convertibles outstanding, $\$ 500$ billion in $2003,{ }^{1} \$ 600$ billion in $2004^{2}$ and, by our estimation, reached $\$ 700$ billion in 2006. The continued expansion and diversity of contractual features of convertibles including different types of call clauses, with or without a hurdle, option to change the conversion ratio, ${ }^{3}$ clauses that restrict the conversion right of holders to contingent events (CoCo clause, conversion based on stock price, CoCoCB clause, conversion based on trading price condition), mandatory clauses, ${ }^{4}$ perpetual feature $^{5}$ and others make convertibles a challenging instrument to price.

Some limited models for valuation of convertibles emerged in the 1960 s, but a theoretically solid framework was first developed by Ingersoll. ${ }^{6} \mathrm{He}$ used a structural approach to derive closed-form solutions for the value of convertible bonds in a variety of special cases. Brennan and Schwartz ${ }^{7}$ developed PDE and boundary conditions under the same assumptions and extended their model ${ }^{8}$ by including stochastic interest rates. The drawback of the structural approach is that the value of the firm is not a traded asset and difficult to estimate.

McConnel and Schwartz ${ }^{9}$ proposed the model in which the basic underlying factor is the issuing firm's stock price, which is traded and easily observed. Tsiveriotis and Fernandes ${ }^{10}$ recognised that equity and debt components of convertible bonds are subject to different default risk and derived a pair of coupled differential equations that can be solved explicitly. Yigitbasioglu ${ }^{11}$ extends this framework to multiple factors in the case of cross-currency convertibles.

As an alternative to the structural approach, a reduced-form approach was pioneered by Jarrow and Turnbull ${ }^{12}$ and Jarrow et al., ${ }^{13}$ It was further extended by Duffie and Singleton, ${ }^{14}$ Davis and Lischka, ${ }^{15}$ Takahashi et al., ${ }^{16}$ Andersen and Buffrum ${ }^{17}$ and others. In this framework, stock price dynamics incorporates default events and it does not drop to 0 immediately in case of default. Ayache et al. ${ }^{18}$ consider a wide variety of assumptions concerning the behaviour of the stock on default and develop hedge strategies under those assumptions.

Despite the variety and complexity of modern models, no complete empirical research on the pricing of convertible bonds has been done. Existing research includes the papers of King, ${ }^{19}$ Carayannopoulos, ${ }^{20}$ Carayannopoulos and Kalimipalli, ${ }^{21}$ Buchan, ${ }^{22}$ Ammann et al. ${ }^{23,24}$ and Alex and Chan. ${ }^{25}$

A drawback of these studies is in the very limited number of instruments analysed and the short studied history of convertibles: King ${ }^{19}$ 
performs his tests for 103 American convertible bonds for two calendar days, Buchan ${ }^{22}$ analyses pricing models for only one day, Carayannopoulus ${ }^{20}$ investigates 30 American bonds for 12 days, Ammann et al. ${ }^{23}$ examine 21 French convertibles for a 1.5-year history (from February 1999 until August 2000). In our research we investigate more that 1,500 CBs quoted on eight leading exchanges ${ }^{26}$ and perform more than one million simulations (more than 2.5 years of historical data per instrument in average).

In this paper we empirically test the ' $\mathrm{CB}$ model' developed by Sophis ${ }^{27}$ from the classic Trinomial model using Tsiveriotis and Fernandes' framework with exogenous credit spread. Although that approach was criticised by some researchers (Ayache et al. ${ }^{18}$ ), it still remains arguably the most popular among practitioners. This is partly due to the fact that practitioners build their investment and hedging strategies based on limited market information, which often makes impossible calibration of more complex models.

The main contributions of this work are as follows:

- we discuss the Tsiveriotis framework in the trinomial context and show its consistency with advanced credit models under some assumptions;

- we investigate use of constant credit spread and empirically prove that it leads to a considerable mispricing of convertible bonds;

- we demonstrate that moving-average credit spread results in a valuation of convertible bonds, which is consistent with the market;

- we prove that historical volatility and implied credit spread are cointegrated for most convertibles in our sample and extend our model to the situation when the bond's market price is not available for some time;

- we empirically test convertible bonds' valuation using credit spread based on a cointegrated relationship with volatility and show that mispricing is statistically insignificant in that case.

The paper is organised as follows: In the next section we discuss the Tsiveriotis and Fernandes approach in trinomial context and the ways to extend it. In the subsequent section we describe the parameterisation of the model used in the empirical research. The penultimate section is devoted to empirical tests of the model without credit spread, with constant credit spread and with moving-average credit spread, respectively. We prove cointegration between historical volatility and implied credit spread in the final section, and empirically investigate the model based on that relationship.

For each empirical research, along with an average model error for all convertibles, we present a chart containing the historical dynamics of market price and theoretical price for some particular convertibles. The examples are average cases used to visualise our hypotheses.

\section{OVERVIEW OF THE TSIVERIOTIS AND FERNANDES APPROACH}

Tsiveriotis and Fernandes (TF) proposed splitting convertible bonds into two components: a 'cash-only' part ( $\left.V^{C O}\right)$ which is subject to credit risk, and a 'share-only' part $\left(V^{S O}\right)$ which is not. Assuming a log normal dynamics for the spot $\mathrm{d} S_{t}=\left(r_{t}-q_{t}\right) S_{t} \mathrm{~d} t+\sigma_{t} S_{t} \mathrm{~d} W_{t}$ they derived a pair of coupled partial differential 
equations that can be solved to value convertibles:

$$
\begin{aligned}
& \frac{\partial V^{C O}}{\partial t}+\left(r_{t}-q_{t}\right) S_{t} \frac{\partial V^{C O}}{\partial S}+\frac{1}{2} \sigma_{t}^{2} S_{t}^{2} \frac{\partial^{2} V^{C O}}{\partial S^{2}} \\
& \quad-\left(r_{t}+c s_{t}\right) V^{C O}=0 \\
& \frac{\partial V^{S O}}{\partial t}+\left(r_{t}-q_{t}\right) S_{t} \frac{\partial V^{S O}}{\partial S}+\frac{1}{2} \sigma_{t}^{2} S_{t}^{2} \frac{\partial^{2} V^{S O}}{\partial S^{2}} \\
& \quad-r_{t} V^{S O}=0
\end{aligned}
$$

where $c_{s t}$ is a credit spread applied to 'cashonly' part of the convertible.

Contractual features mentioned in the Introduction make it impossible to price modern convertibles by some closed formula or reasonable number of partial differential equations. The trinomial method, a simple description of which can be found in $\mathrm{Hull}^{28}(\mathrm{p}$. 408), ideally suits such a purpose. Indeed, by working backward through the tree and, if needed, adding additional layers to the tree (reset clause), it is possible to handle many of the existing features.

The TF framework in the trinomial context is easily extended to incorporate probability of issuer's default $\left(P\left(t_{1}, t_{2}\right)\right)$ determined by a specific hazard rate $(\lambda(s))$ :

$$
P(0, t)=1-\exp \left(-\int_{0}^{t} \lambda(s) \mathrm{d} s\right)
$$

Having credit default swaps with the same issuer quoted on the market, we can calibrate a hazard rate. Without loss of consistency with the available market information, we can assume that $\lambda(s)$ is a piecewise constant function discontinuous in each maturity of the calibrating instrument.
Using the following notations:

$B(t, T)$ - riskless discount factor between $t$ and $T$,

$\delta$ - recovery rate,

the price of any zero coupon, which is credit risky, is given by the following arbitrage argument:

$$
\begin{aligned}
& B_{\text {risky }}(t, T, \delta)=(1-P(t, T)) B(t, T) \\
& +P(t, T) \delta B(t, T)= \\
& \quad B(t, T)\left[\delta+(1-\delta) \exp \left(-\int_{t}^{T} \lambda(s) \mathrm{d} s\right)\right]
\end{aligned}
$$

Making a very general assumption about recovering some part of the convertible bond $V_{R}(t)$, we can implement the following trinomial algorithm for its valuation:

$$
\begin{gathered}
\tilde{V}_{i, j}^{S O}=B\left(t_{i}, t_{i+1}\right)\left(p_{u} V_{i+1, j+1}^{S O}+p_{m} V_{i+1, j}^{S O}\right. \\
\left.+p_{\mathrm{d}} V_{i+1, j-1}^{S O}\right) \\
\tilde{V}_{i, j}^{C O}=B_{r i s k y}\left(t_{i}, t_{i+1}\right)\left(p_{u} V_{i+1, j+1}^{C O}+p_{m} V_{i+1, j}^{C O}\right. \\
\left.+p_{\mathrm{d}} V_{i+1, j-1}^{C O}\right)+ \\
C P_{i}+\delta \int_{t_{i}}^{t_{i+1}} V_{R}(s) B\left(t_{i}, s\right) \mathrm{d} P\left(t_{i}, s\right) \\
\tilde{V}_{i, j}=\tilde{V}_{i, j}^{S O}+\tilde{V}_{i, j}^{C O}
\end{gathered}
$$

Then, without any special clauses, the value of convertible is given by

$$
V_{i, j}=\max \left(\tilde{V}_{i, j}, C V_{i, j}\right)
$$

Finally,

$$
\left\{\begin{array}{cc}
V_{i, j}^{C O}=0 & \text { if } V_{i, j}=C V_{i, j} \\
V_{i, j}^{C O}=\tilde{V}_{i, j}^{C O} & \text { if } V_{i, j}=\tilde{V}_{i, j} \\
V_{i, j}^{C O}=V_{i, j} & \text { otherwise (special clauses) }
\end{array}\right.
$$


and

$$
V_{i, j}^{S O}=V_{i, j}-V_{i, j}^{C O}
$$

Market practitioners usually use one of two assumptions for recovery of a convertible: either the notional or bond part is recovered. In the second case it becomes a classical TF model with credit spread modelled as follows:

$$
c s\left(t, t_{1}, \Delta t\right)=-\frac{1}{\Delta t} \ln \left[\delta+\exp \left(-\int_{t_{1}}^{t_{1}+\Delta t} \lambda(t, s) \mathrm{d} s\right)\right]
$$

For trinomial implementation of the TF model, the time to maturity is divided into a number of equal time intervals. For a particular implementation, the credit spread is a function of two arguments: pricing date $t$ and future time $t_{1}$. With a large number of steps, credit spread is a piecewise constant function with respect to the second argument having $n-1$ points of discontinuity (where $n$ is the number of instruments calibrating hazard rate). When pricing a convertible, it is often the case that practitioners do not have market information available for modelling a hazard rate or have very limited information (often only one instrument). Thus, the assumption that credit spread is a constant with respect to the future dates is often made.

The TF framework was criticised by Ayache et al. ${ }^{18}$ for the independence of the CB value of the credit risk when it is called just before the redemption date, for its inability to incorporate a partial recovery of the stock price and maintain a dynamic hedge. The first is clearly not a problem in the implementation presented above (see formula (2)). The second can be overcome in a trinomial context by assuming the following stock process:

$$
\begin{aligned}
\frac{\mathrm{d} S(t)}{S(t-)}= & \left(r(t)-q(t)+\left(1-R_{S}\right) \lambda(t-)\right) \mathrm{d} t \\
& +\sigma(t) \mathrm{d} W(t)-\left(1-R_{S}\right) \mathrm{d} N(t)
\end{aligned}
$$

where $S(t-)$ is the stock price immediately before $t, R_{S}$ is the fraction of the pre-default value of the stock that can be recovered in case of default, and the drift term $\lambda(t-)$ compensates for the expected downward drift of the Poisson process. It is required for the process to satisfy that

$$
\left.S(t) \exp \left(-\int_{0}^{t} r(u)-q(u)\right) \mathrm{d} u\right)
$$

be a martingale in the risk-neutral probability measure.

After default some cash is recovered and the stock ceases to exist so the dynamics of the post-default stock should be changed to $\mathrm{d} S(t)=r(t) S(t) \mathrm{d} t$.

Within that model, hedging of convertible $V$ can be maintained taking a position in a corporate bond $B$ and the stock itself. Let $h_{B}$ and $h_{S}$ be the hedge positions in bond and stock. For the hedging portfolio $\Pi(t)=V(t)+$ $h_{B} B(t)+h_{S} S(t)+$ cash to be risk neutral all $\mathrm{d} W(t)$ and $\mathrm{d} N(t)$ terms for $\mathrm{d} \Pi(t)$ must be set to 0 , which leads to the following formulae:

$$
\begin{gathered}
h_{B}=\frac{R_{V}(t)-V(t)+\partial V(t) / \partial S}{B-R_{B}-(\partial B(t) / \partial S) S(t)} \\
h_{S}=-\frac{\partial V(t)}{\partial S}-h_{B} \frac{\partial B(t)}{\partial S}
\end{gathered}
$$

Altogether, despite recent advances in credit derivatives theory, the TF framework still remains arguably the most popular among 
practitioners. It is the most effective approach for firms whose credit is illiquid or does not trade at all. The TF framework is easily extended to incorporate default probability of the issuer and recovery of the bond part of the convertible.

In this paper, we investigate the pricing performance of the TF approach and propose its practical implementation leading to a pricing consistent with a market.

\section{PARAMETERISATION OF TRINOMIAL MODEL USED IN THE EMPIRICAL ANALYSIS}

In our empirical research, we adopt the approach of incorporating a constant exogenous credit spread (with respect to the second argument, formula (3)) into a trinomial model. As discussed above, this assumption is often made when limited or no market (credit) information is available and it is theoretically consistent with advanced credit risk models.

We assume a lognormal dynamics for the spot.

The relevant volatility is computed as a standard deviation of the returns for the last 20 days.

The riskless discount factor is retrieved from the zero coupon yield curve, which is based on zero coupon rates for short maturities and swap rates for long maturities ( $>1$ year) for each currency.

\section{EMPIRICAL ANALYSIS}

In the first empirical experiment, we calculated the average deviation of the theoretical value given by the $\mathrm{CB}$ model without using any credit spreads derived from (or based on) the closing market price of the CB. Averaging was performed for all historical simulations $\left(\sum_{\text {hist }}\right)$ for a particular $\mathrm{CB}$ and for all $\mathrm{CBs}\left(\sum_{C B^{\prime}}\right)$ :

$$
E r r=\frac{\sum_{C B^{\prime} s} \sum_{h i s t}\left|C B_{t h}-C B_{m k t}\right|}{N}
$$

where $C B_{m k t}$ is the closed price of the $\mathrm{CB}$ and $\mathrm{CB}_{\text {th }}$ is the theoretical value given by ' $\mathrm{CB}$ model'.

The average error of the pricing was Err $\approx 15.798$ per cent. Considering the fact that intraday fluctuations for $\mathrm{CB}$ prices can be up to 5 per cent, the error is unacceptably high.

Let us consider an example: CB 'TASAKI SHINJU 1.3 per cent' with issue date $=01 / 09 /$ 97 and end date $=30 / 10 / 2006$. Historical data used for the empirical analysis are from 31/07/ 1997 until 26/07/2005 (almost the entire life of the $\mathrm{CB}$ ). Approximately 1,500 simulations were done. The average error of the 'CB model', without using credit risk, was 19.175 per cent.

Figure 1 shows the CB's market price (heavy line) and the theoretical value (thin line). It is obvious that $\mathrm{CB}$ was overpriced during its entire life. The main reason for the error in the first empirical analysis was the fact that credit risk associated with $\mathrm{CBs}$ was not taken into account. The high credit risk of the $\mathrm{CB}$ makes it less attractive for investors thus reducing its price. Close to the redemption date, credit risk has a very small impact on the pricing, which can be seen in Figure 1 where, in the end, theoretical value and the market price become close to each other.

The important result of that empirical test is that the pricing of highly rated convertible bonds is consistent with the market. Obviously, for such convertibles a good pricing model with proper chosen parameters should value the convertible bond close to the market without any credit information used (zero credit spread). 


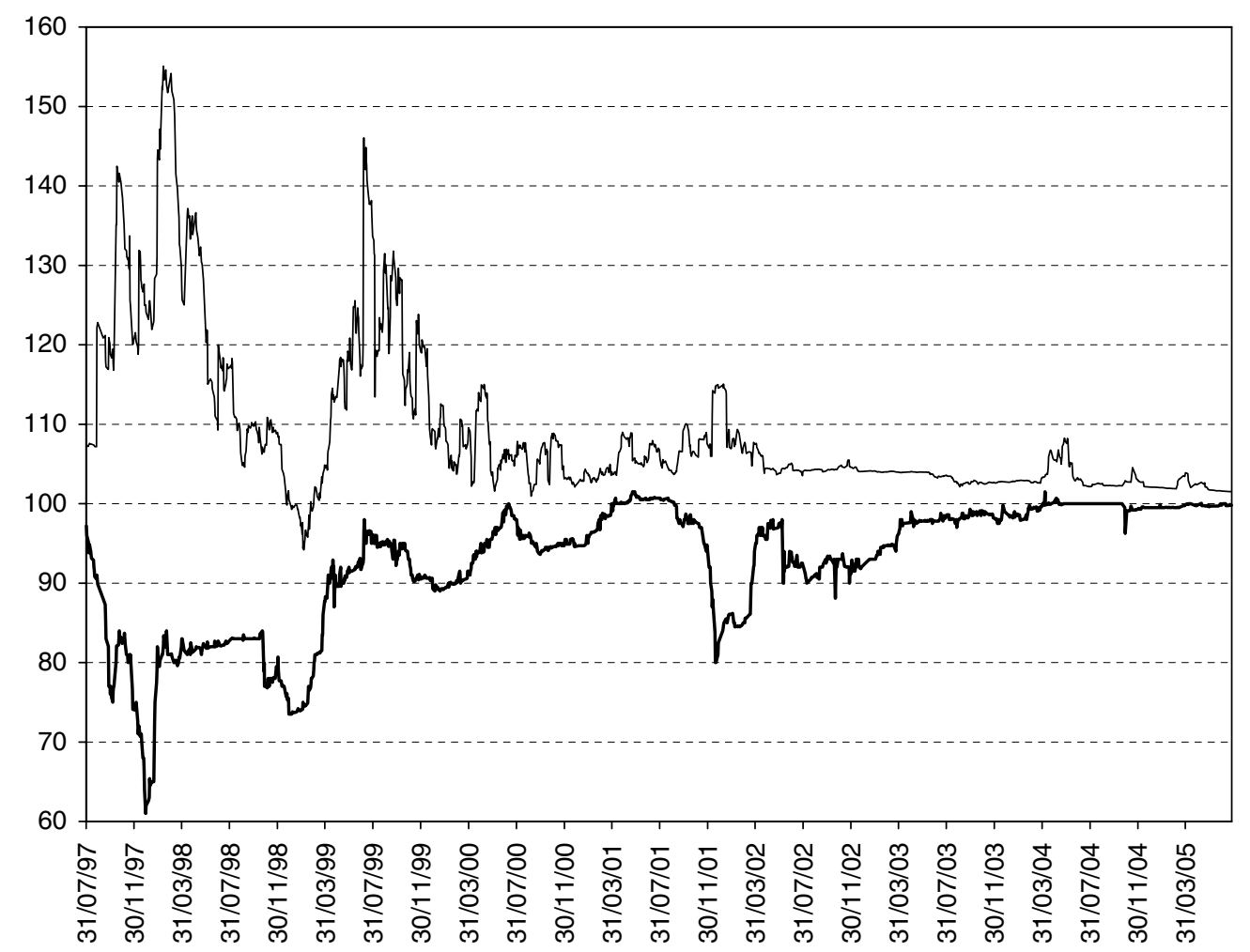

Figure 1: Comparison of the closed market price (heavy line) of the 'TASAKI SHINJU 1.3 per cent' with its theoretical value without using credit spread (thin line)

For CBs with S\&P credit ratings AAA, AA or A (117 in total), the average error of the model was Err $\approx 3.436$ per cent. The error is statistically not significant, supporting our choice of observable from the market parameters, including historical volatility and zero coupon yield curve, and forms good grounds for investigating how credit risk can be modelled within the TF framework.

Figure 2 shows the market price and theoretical value of CB 'FRANKLIN RESOURCES 0 per cent 2031' rated as A by S\&P on $10 / 05 / 2001$. The deviation of the theoretical value from the market price is much smaller than in the previous example. It is worth noting that the noticeable divergence of two lines at some points is due to macroeconomic or geopolitical events. A widespread pessimism after September 11, 2001 pushed the market price of the convertible down and increased the underlying's volatility, resulting in an increased theoretical value of the $\mathrm{CB}$ (that particular $\mathrm{CB}$ has a put clause and conversion right to contingent events).

The next step in our empirical analysis was finding a simple yet effective way of modelling the credit spread of convertible bond.

Considering that if no default occurs, the credit rating of the $\mathrm{CB}$ does not usually change, or changes inconsiderably, we test a simple approach of using a constant credit spread (formula (3)) with respect to the first argument (ie we are assuming that it is not changing 


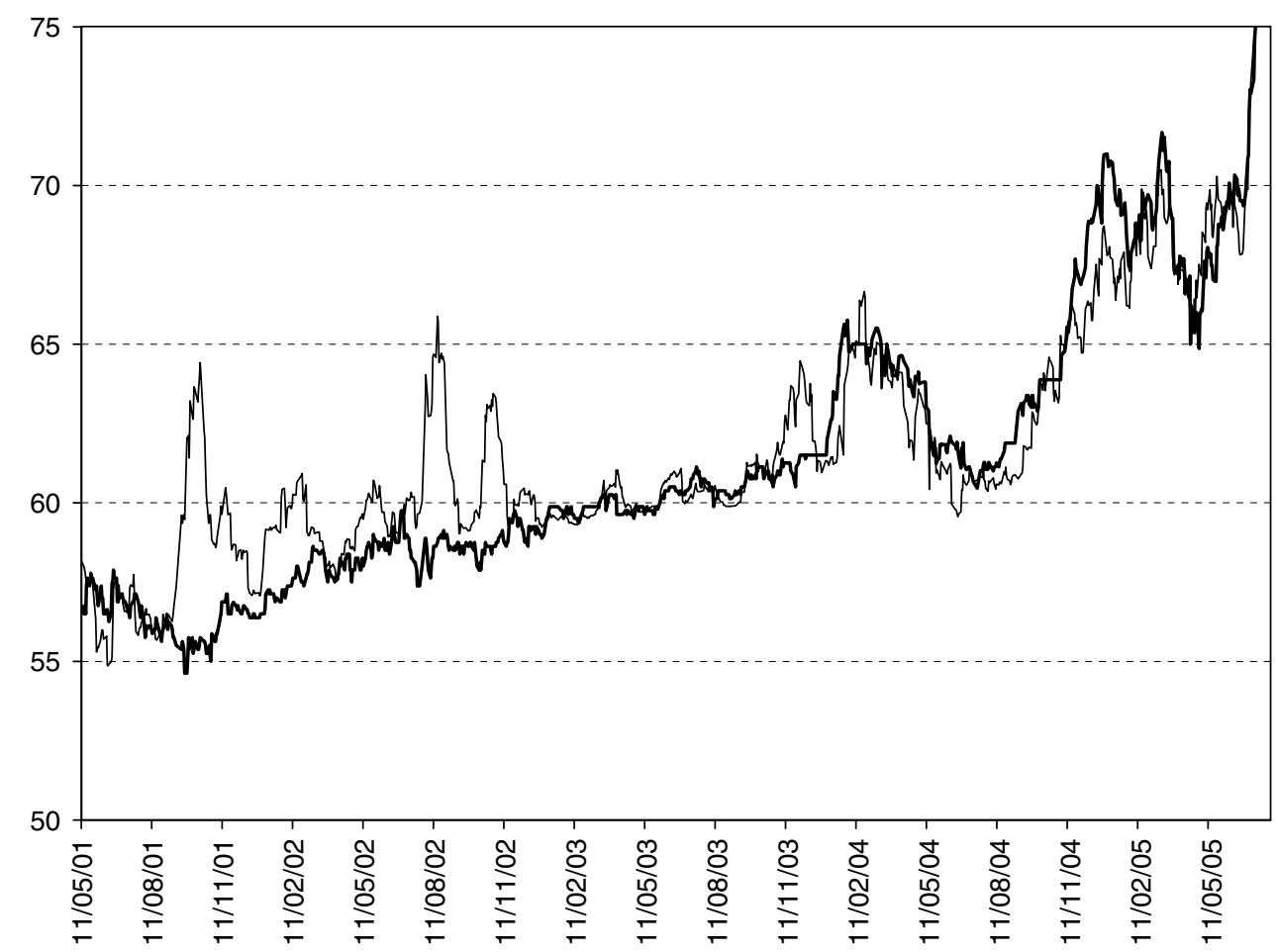

Figure 2: Comparison of the closed market price (heavy line) of CB 'FRANKLIN RESOURCES 0 per cent' rated as $A$ by S\&P with its theoretical value without using credit spread

through the life of the convertible). For that, we calculate the credit spread associated with CB averaging implied credit spread ( $c s_{\text {implied }}$ ) for the entire history:

$$
c s_{a v}=\frac{1}{N} \sum_{\text {hist }} c s_{i}^{\text {implied }}
$$

For the example used above, CB 'TASAKI SHINJU 1.3 per cent', the average implied credit spread $c s_{a v} \approx 3.754$ per cent. The average error of the model was 9.1 per cent (see Figure 3) against 19.175 per cent in the first experiment.

Empirical analysis of the CB model using average implied credit spread for all CB's produced the average error $E r r \approx 6.854$ per cent, an improvement on the previous result of 15.798 per cent. The reason for the continuing high error is due to the fact that, unlike credit rating, credit spread has a stochastic nature. It reflects the trader's continually changing perception of the riskiness of the $\mathrm{CB}$.

Another approach would be to use movingaverage implied credit spread. In our third empirical experiment, we decided to use implied credit spread averaged for the last two months prior to calculation. For CB 'TASAKI SHINJU 1.3 per cent', the average error was 3.289 per cent (see Figure 4).

For all CBs, the average error was Err $\approx 3.699$ per cent. Considering the fact that the intraday fluctuations for a CB's price could be as much as 5 per cent, this result proves the high accuracy of the third approach. 


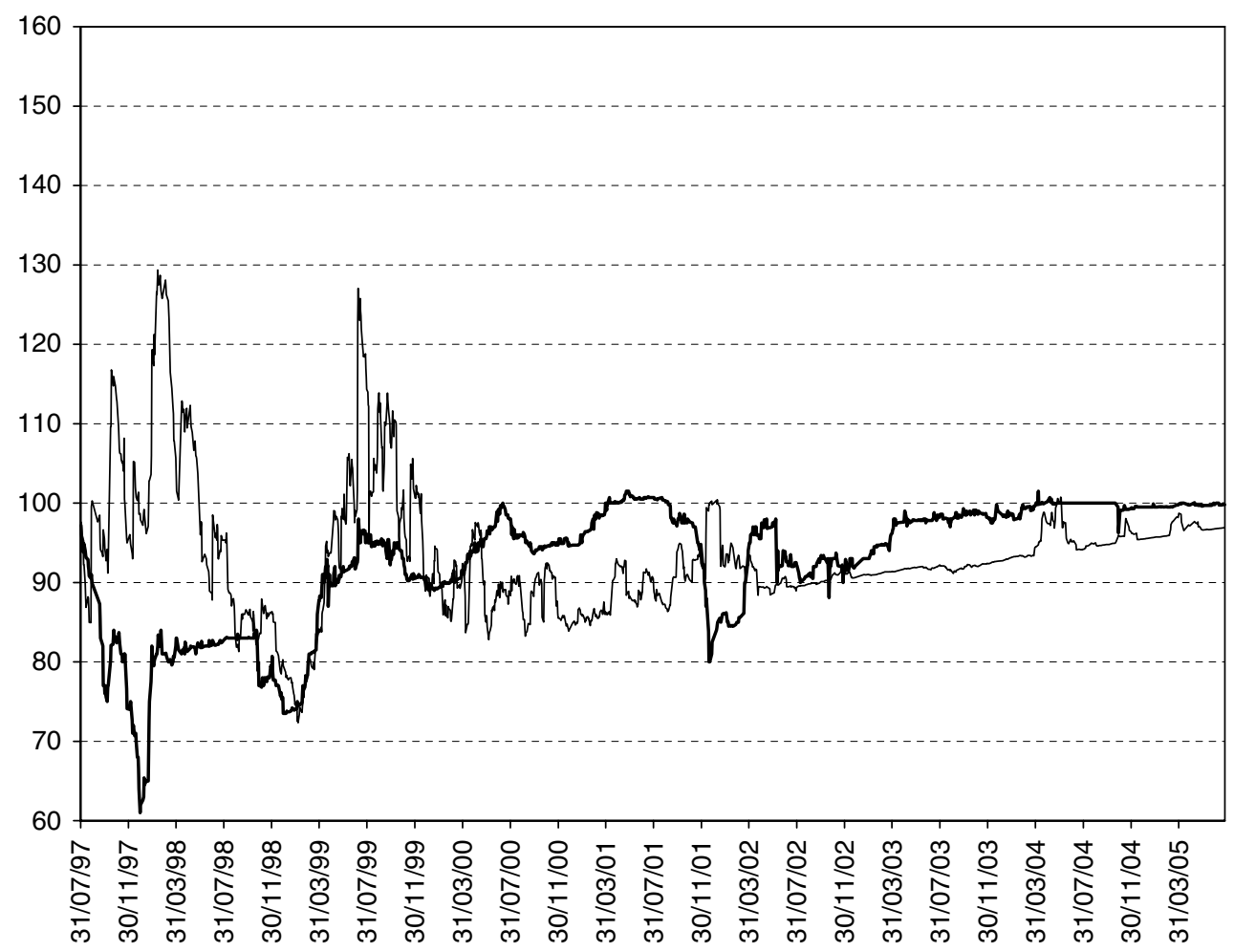

Figure 3: Comparison of the market price (heavy line) of CB 'TASAKI SHINJU 1.3 per cent' with its theoretical value calculated using average implied credit spread (thin line)

To further improve the moving-average approach, it is necessary to adjust the length of the history used in the credit spread calculation. A variety of factors such as default events and important market information would affect it considerably and sometimes change it suddenly. As a result, the moving-average value would react to such changes with some time lag and would always lag behind the rapidly changing real credit value.

Therefore, it is necessary to capture such events and shorten the history for the movingaverage credit risk at that point and increase it gradually to the normal length afterwards. For example, consider CB 'INFOGRAMES ENTERTAINMENT 1.5 per cent (OCEANE)
2005'. Its underlying price dropped from 29.3173 on $30 / 05 / 2000$ to 1.6599 on $04 / 07 /$ 2005 (see Figure 5).

Figure 6 shows that the CB's theoretical value with moving-average credit spread is always behind its market value. As a consequence of modelled credit spreads always reacting late to the changes in the implied credit spread, the average error of the model was 9.564 per cent, which is too far from the acceptable value. The natural indicator of the sharp changes in the issuer's credit risk would be its historical volatility.

Figure 7 displays the historical volatility of the CB's underlying equity price and barriers, within which lie more than 95 per cent of the 

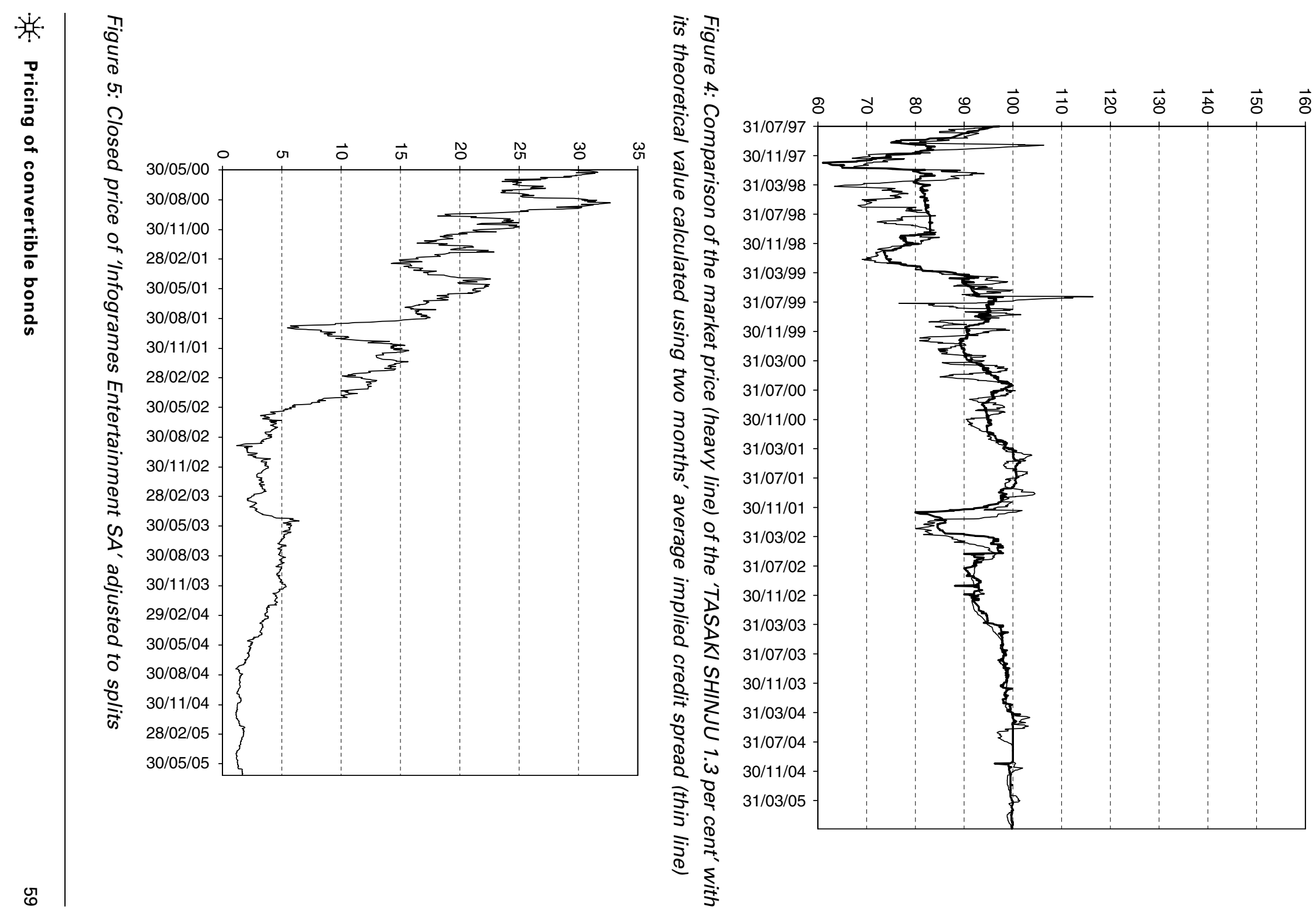


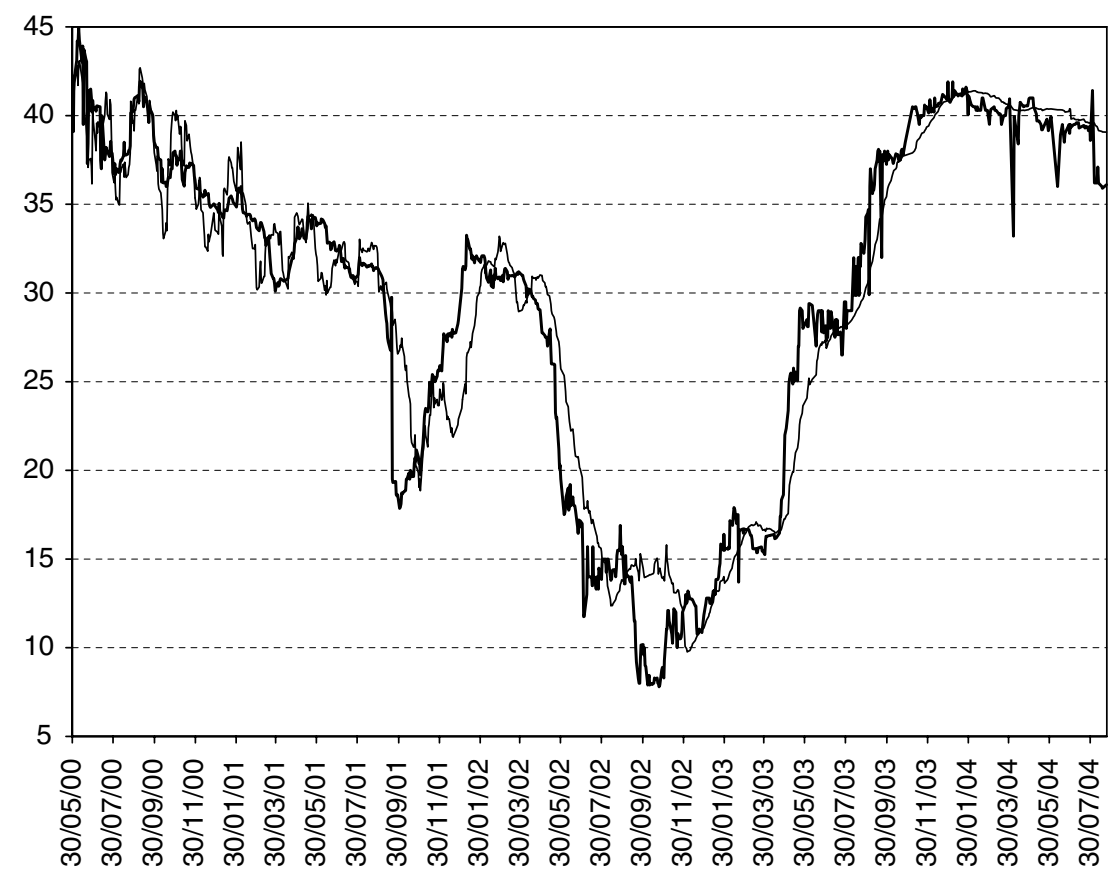

Figure 6: Comparison of the market price (heavy line) of CB 'INFOGRAMES ENTERTAINMENT 1.5 per cent (OCEANE) 2005' with its theoretical value calculated using two months' average implied credit spread (thin line)

volatility's values. Each time the volatility hits the barrier suggests that some event has occurred, and the time length for calculating the movingaverage credit spread should be reset to one day with a further gradual increase to the twomonths' length. Indeed, it can be seen in Figure 7 that the barrier was hit on 19/09/2001, which coincides with the time interval when the CB's theoretical value became delayed from its market value. Before that day, the average error was 3.8967 per cent.

Alternatively, the weighting scheme can be used for modelling moving-average credit spread. Deviation of historical volatility from its long-run average should result in less weight given to older observations. Both approaches - adjusting number of days for moving-average credit spread calculation and changing weights according to jumps of the historical volatility - will further improve the pricing for all CBs.

The result of third test is important for a number of reasons. First of all, it empirically proves the existence of continuous and smooth credit spread function using which, in the TF approach, results in a valuation of convertible consistent with the market. As a consequence of this, it is possible to hedge convertible within the TF framework. In practice it is necessary to find an implied credit spread for number of days in the past and construct a portfolio consisting of convertible, underlying share and other instruments sensitive to credit spread (credit default swap, bond, etc). Secondly, it establishes some sort of benchmark for the expected mispricing within the TF approach. Any model 


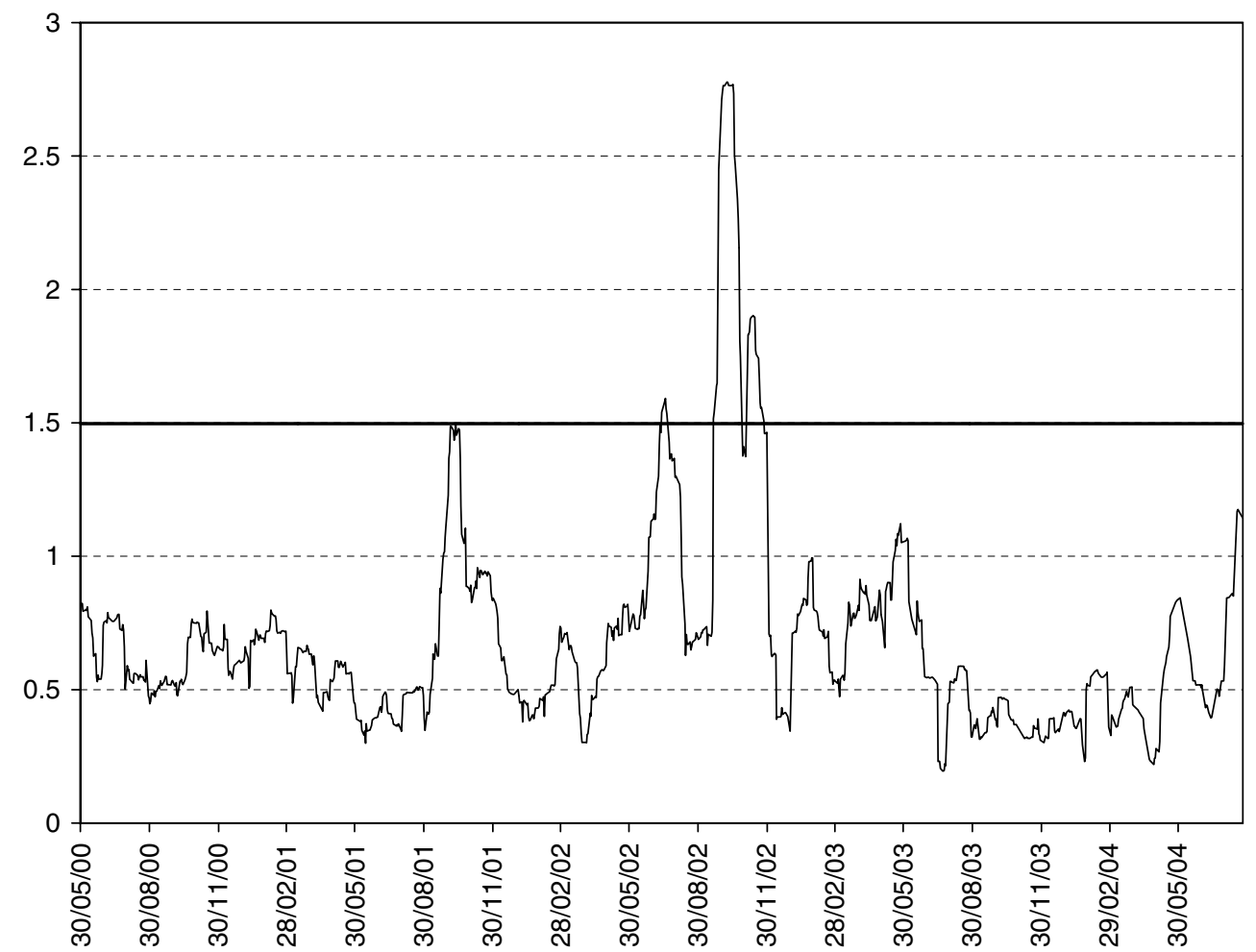

Figure 7: Historical volatility of the 'Infogrames Entertainment $S A^{\prime}$ and barriers within which more than 95 per cent of values lie

within that approach would result in average similar or worse pricing.

\section{COINTEGRATION BETWEEN HISTORICAL VOLATILITY AND CREDIT RISK OF CONVERTIBLE BOND}

The obvious drawback of the moving-average approach is the requirement for the market prices of convertibles in order to calculate the credit spread. It is impossible to price a CB using that approach without recent historical implied credit risk. Our purpose was to find a way of modelling credit spread without using the CB market price. Following the idea of capturing default events by monitoring historical volatility of the underlying share, we investigated whether there is a relationship between implied credit risk of the $\mathrm{CB}$ and historical volatility of its underlying share, when the underlying share is issued by the same company.

The average correlation between implied credit spread and historical volatility calculated for $1,358^{29}$ convertibles was 66.6413 per cent. Our hypothesis was that the same stochastic source of uncertainty lies behind both processes. We validated the hypothesis that implied that credit spread and volatility are cointegrated stochastic processes, that is, they are related by the following formula:

$$
\begin{aligned}
\operatorname{Credit}(t) & =\alpha+\beta * \operatorname{Volatility}(t) \\
& +\hat{u}(t), \quad \hat{u}(t) \sim I(0)
\end{aligned}
$$




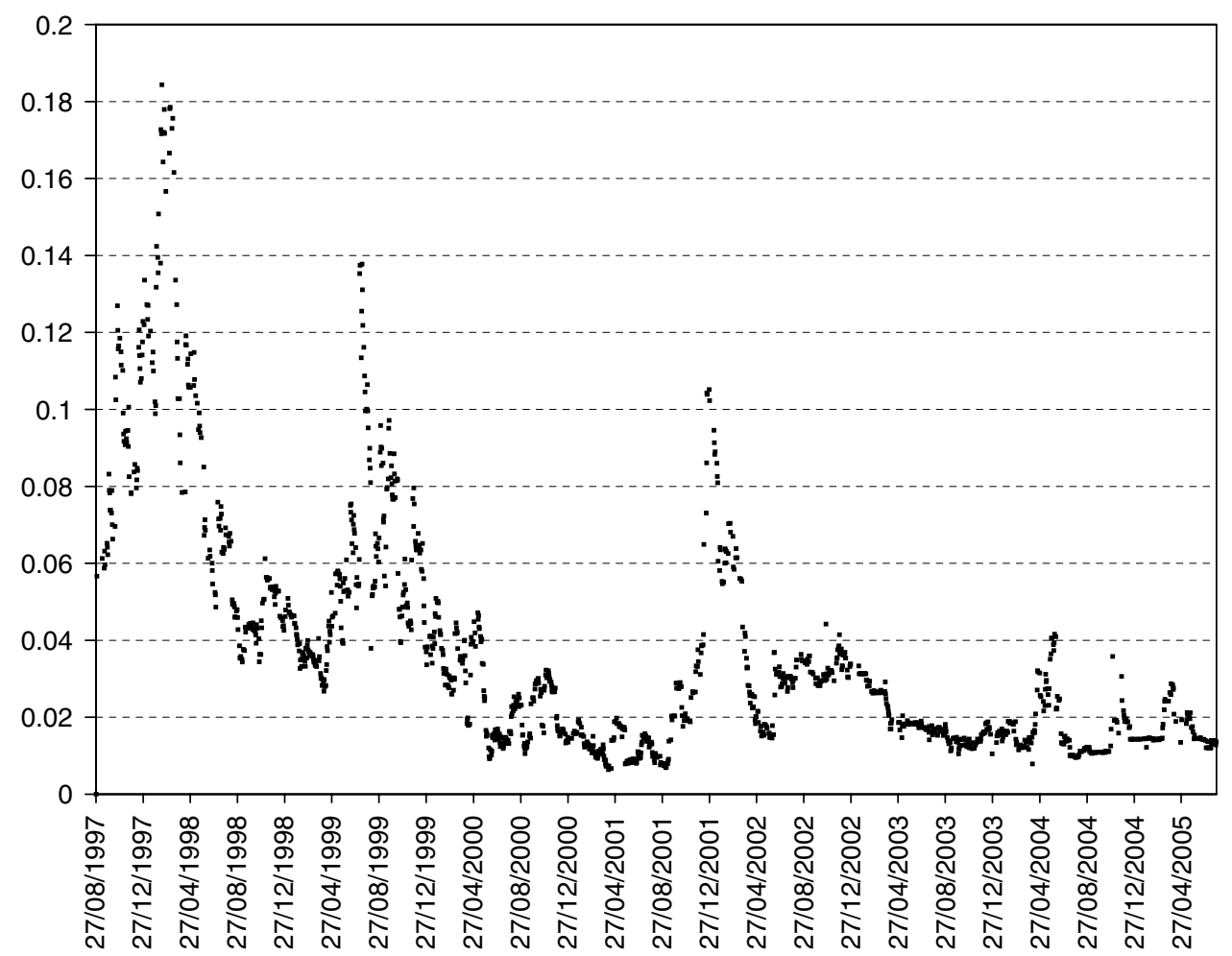

Figure 8: Implied credit spread of CB 'TASAKI SHINJU 1.3 per cent'

For validation of our hypothesis, we used two residual-based tests proposed by Phillips and Ouliaris ${ }^{30}-\hat{P}_{u}$ and $\hat{P}_{z}$ tests.

In general, let $z_{t}$ be an $(n+1)$-vector integrated process whose generating mechanism is

$$
z_{t}=c+\Pi z_{t-1}+\xi_{t}
$$

where $\Pi$ is the coefficient matrix and $\xi_{t}$ is an $(n+1)$ zero mean white noise vector process with time-invariant covariance matrix

$$
\boldsymbol{\Omega}=\lim _{T \rightarrow \infty} T^{-1} E\left(\sum_{1}^{T} \xi_{t}\right)\left(\sum_{1}^{T} \xi_{t}^{\prime}\right)
$$

Let $\hat{\xi}_{t}$ be the residuals from the least-squares regression with a fitted intercept:

$$
z_{t}=c+\hat{\Pi} z_{t-1}+\hat{\xi}_{t}
$$

Then, for some choice of lag window such as $w_{s l}=1-s /(l+1)\left(\right.$ Phillips and Durlauf $\left.{ }^{31}\right)$

$$
\begin{gathered}
\hat{\Omega}=T^{-1} \sum_{t=1}^{T} \hat{\xi}_{t} \hat{\xi}_{t}+T^{-1} \sum_{s=1}^{l} w_{s l} \\
\sum_{t=s+1}^{T}\left(\hat{\xi}_{t} \hat{\xi}_{t-s}^{t}+\hat{\xi}_{t-s} \hat{\xi}_{t}^{t}\right)
\end{gathered}
$$

is a consistent estimator of the covariance matrix that is based on the residuals $\hat{\xi}_{\text {t. }}$.

We partition $z_{t}=\left(y_{t}, x_{t}\right)$ into the dependent variate $y_{t}$ and the explanatory $n-$ vector $x_{t}$ with the following partition of $\hat{\Omega}$ :

$$
\hat{\Omega}=\left(\begin{array}{cc}
\hat{\omega}_{11} & \hat{\omega}^{\prime} 21 \\
\hat{\omega}_{21} & \hat{\Omega}_{22}^{1}
\end{array}\right){ }_{n}^{1}
$$




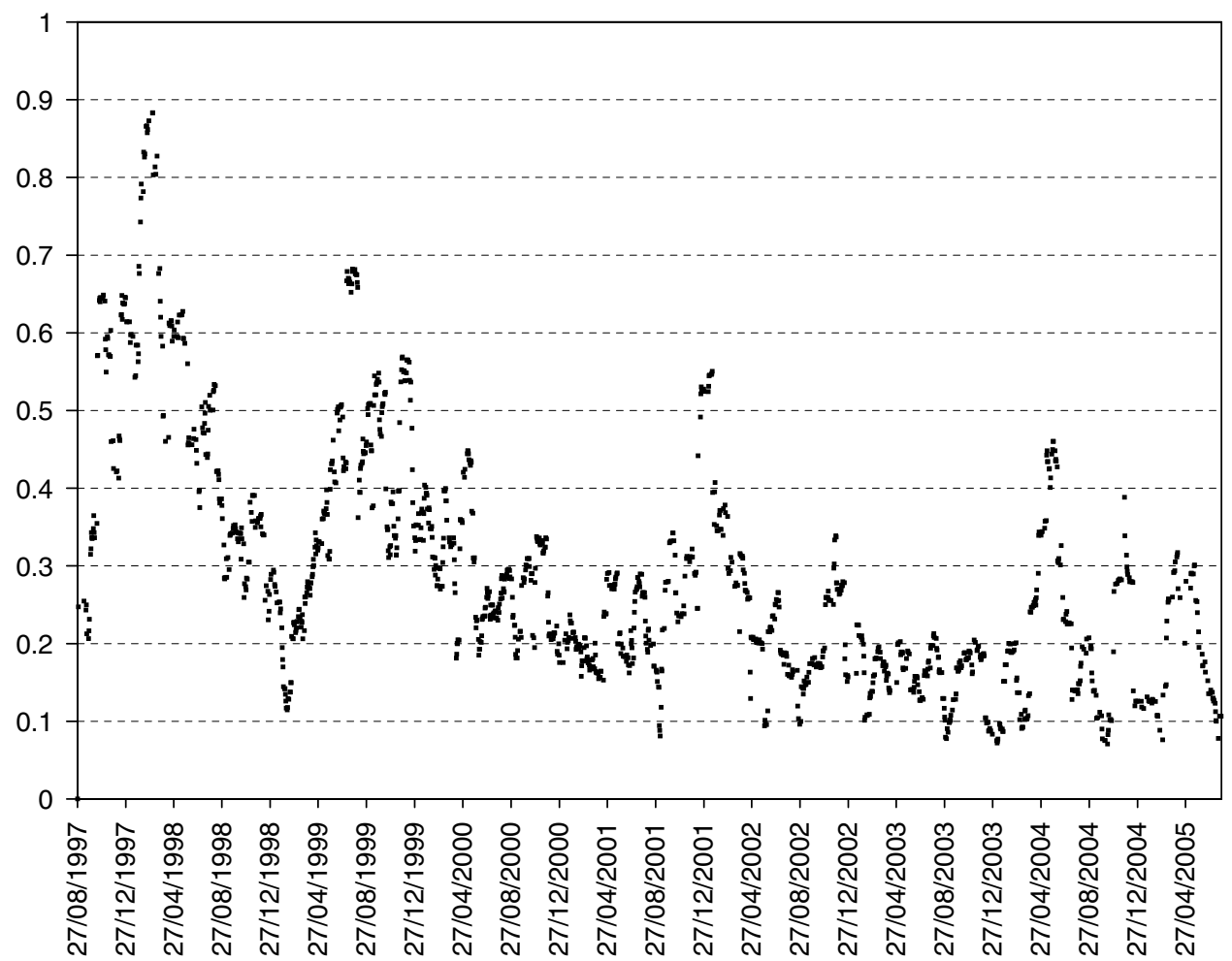

Figure 9: Historical volatility of CB 'TASAKI SHINJU 1.3 per cent'

$\hat{P}_{u}$ is a variance ratio test with test statistics:

$$
\hat{P}_{u}=\frac{T \hat{\omega}_{112}}{\left(T^{-1} \sum_{t=1}^{T} \hat{u}_{t}^{2}\right)}
$$

It measures the size of the residual variance from the cointegrating regression of $y_{t}$ on $x_{t}$ $\left(T^{-1} \sum_{t=1}^{T} \hat{\mathrm{u}}_{t}^{2}\right)$ against that of a direct estimate of the population conditional variance of $y_{t}$ given $x_{t}$ $\left(T \hat{\omega}_{112}=\mathrm{T}\left(\hat{\omega}_{11}-\hat{\omega}_{21}^{\prime} \hat{\Omega}_{22}^{-1} \hat{\omega}_{21}\right)\right)$.

$\hat{P}_{z}$ is a multivariate trace statistics:

$$
\hat{P}_{z}=\operatorname{Ttr}\left(\hat{\Omega} M_{z z}^{-1}\right)
$$

where $M_{z z}=T^{-1} \sum_{t=1}^{T} z_{t} z_{t}^{\prime}$ is the observed sample moment matrix.

Both $\hat{P}_{u}$ and $\hat{P}_{z}$ tests were done for all 1,358 CBs. The hypothesis of no-cointegration was rejected by $\hat{P}_{z}$ test for 90.77 per cent and by $\hat{P}_{u}$ for 82.73 per cent of tested CBs.

Randomly checking unsuccessful CBs showed different kinds of problems because of incorrect historical data.

For the example we discussed earlier, 'TASAKI SHINJU 1.3 per cent', you can see Implied credit spread in Figure 8 and historical volatility in Figure 9. For both tests the hypothesis of no-cointegration was rejected on a 1 per cent level. The average error of the theoretical value with credit spread based on the historical volatility for CB 'TASAKI SHINJU 1.3 per cent' was 4.86 per cent.

For all 1,330 CBs, empirical analysis produced an average error $E r r \approx 4.12$ per cent, which is almost as good as for moving-average credit spread (3.699 per cent). It proves our hypothesis and makes it possible to use the TF framework 
with exogenous credit risk based on the historical volatility. If the standard deviation of the white noise $\hat{u}(t)(4)$ is small compared to the credit risk value, then the model should produce a very accurate result. In practice, the model needs to be calibrated based on existing historical data. If cointegration is proven and standard deviation of residuals is small compared to credit spread, then the model can be adapted.

\section{RESUME}

1 Results of the empirical research show that the TF approach for pricing modern CBs with complicated clauses based on the trinomial algorithm using credit spread produces very accurate result.

2 The average errors of the model without using credit spread, with using average credit spread and with using moving-average credit spread were 15.798; 6.854; and 3.699 per cent, respectively.

3 Credit spread and historical volatility were proved to be cointegrated processes, for most CBs, using two residual-based tests $\left(\hat{P}_{u}\right.$ and $\left.\hat{P}_{z}\right)$ proposed by Phillips and Ouliaris.

4 The average error of the model using credit spread based on historical volatility was 4.12 per cent. It is especially important that the only market information used for the model was current underlying share prices.

\section{Acknowledgments}

We thank Tatiana Liber, Edward Gilmore, and Nelson Abbey for their suggestions and comments.

\section{References and Notes}

1 Schultz, A. (2002) 'In These Convertibles, a Smoother Route to Stocks', The New York Times, 7 April.
2 Sungard (2004) 'How French institutions are pricing convertible bonds',http://www.sungard.com/Monis/ default.aspx?id $=6$.

3 Hoogland, J.K., Neumann, C.D.D. and Bloch, D. (April 2001) 'Converting the Reset', Technical Report SEN-R010, CWI, Stiching Matematisch Centrum, Amsterdam, Netherlands.

4 Arzac, E.R. (1997) 'PERCS, DECS, and Other Mandatory Convertibles', Journal of Applied Corporate Finance, Vol. 10, pp. 54-63.

5 Sirbu, M., Pikovsky, I. and Shreve, S. (2004) 'Perpetual Convertible Bonds', SIAM Journal of Control and Optimization, Vol. 43, No. 1, pp. 58-85.

6 Ingersoll Jr., J. (1977) 'A Contingent-Claims Valuation of Convertible Securities', Journal of Financial Economics, Vol. 4, No. 3, pp. 289-321.

7 Brennan, M.J. and Schwartz, E.S. (1977) 'Convertible Bonds: Valuation and Optimal Strategies for Call and Conversion', Journal of France, Vol. 32, pp. 1699-1715.

8 Brennan, M.J. and Schwartz, E.S. (1980) 'Analyzing Convertible Bonds', Journal of Financial and Quantitative Analysis, Vol. 15, pp. 907-929.

9 McConnel, J.J. and Schwartz, E.S (1986) 'LYON Taming', Journal of Finance, Vol. 41, pp. 561-576.

10 Tsiveriotis, K. and Fernandes, C. (1998, September) 'Valuing Convertible Bonds with Credit Risk', Journal of Fixed Income, Vol. 8, pp. 95-102.

11 Yigitbasioglu, A.B. (2002) 'Pricing Convertible Bonds with Interest Rate, Equity, Credit and FX risk', ISMA Center, University of Reading, UK.

12 Jarrow, R.A. and Turnbull, S.M. (1995) 'Pricing Derivative Securities on Financial Securities Subject to Credit Risk', Journal of finance, Vol. 50, pp. 53-85.

13 Jarrow, R.A., Lando, D. and Turnbull, S.M. (1997) 'A Markov Model for the Term Structure of Credit Spreads', The Review of Financial Studies, Vol. 10, pp. 481-523.

14 Duffie, D. and Singleton, K.J. (1999) 'Modelling Term Structures of Defaultable Bonds', Review of Financial Studies, Vol. 12, pp. 687-720.

15 Davis, M. and Lischka, F.R. (1999) 'Convertible Bonds with Market and Credit Risk', Working Paper, TokyoMitsubishi International plc.

16 Takahashi, A., Kobayashi, T. and Nakagawa, N. (2001, December) 'Pricing Convertible Bonds with Default Risk', Journal of Fixed Income, Vol. 11, pp. 20-29.

17 Andersen, L. and Buffrum, D. (2003) 'Calibration and Implementation of Convertible Bonds Models', Working Paper, Banc of America Securities.

18 Ayache, E., Vertzal, K.R. and Forsyth, P.A. (2002, December) 'Next Generation Models for Convertible Bonds with Credit Risk', Wilmott Magazine, pp. 68-77. 
19 King, R. (1986) 'Convertible Bond Valuation: An Empirical Test', Journal of Financial Research, Vol. 9, No. 1, pp. 53-69.

20 Carayannopoulos, P. (1996) 'Valuing Convertible Bonds under the Assumption of Stochastic Interest Rate: An Empirical Investigation', Quaterly Journal of Business and Economics, Vol. 35, No. 3, pp. 17-31.

21 Carayannopoulos, P. and Kalimipalli, M. (2003) 'Convertible Bond Prices and Inherent Biases', Working Paper, The Mutual Group Financial Services Reseach Center, School of Business and Economics, Wilfrid Laurier University.

22 Buchan, J. (1997) 'Convertible Bond Pricing: Theory and Evidence', Unpublished Dissertation, Harvard University.

23 Ammann, M., Kind, A. and Wilde, C. (2003) 'Are Convertible Bonds Underpriced? An Analysis of the French Market', Journal of Banking and Finance, Elsevier, Vol. 27, No. 4, pp. 635-653.

24 Ammann, M., Kind, A. and Wilde, C. (2005) 'Simulation-Based Pricing of Convertible Bonds', Working Paper, University of St. Gallen and University Frankfurt.
25 Chan, A.W.H. and Chen, N. (2007) 'Convertible Bond Underpricing: Renegotiable Covenants, Seasoning, and Convergence', Management Science, Vol. 53, No. 11, pp. 1793-1814.

26 'NY Stock Exchange' - 638, NASDAQ - 389, Tokyo - 298, 'Taiwan Stock Exchange' - 97, 'Monep' - 80, UK - 68, 'Korea Stock Exchange' 65, 'Swiss Exchange' - 52, others - 315.

27 Sophis Technology (2006) 'RISQUE Financial Documentation', Sophis Technology, 6th edn.

28 Hull, J. (2006) 'Options, Futures and other Derivatives', 6th edn, Prentice-Hall, Upper Saddle River, NJ.

29 The rest were excluded due to different reasons: lack of data, impossibility to compute implied credit spread for some highly rated CBs (for them the error of the model were $<2-3$ per cent) etc.

30 Phillips, P.C.B. and Ouliaris, S. (1990) 'Asymptotic Properties of Residual Based Tests for Cointegration', Econometrica, Vol. 58, No 1, pp. 165-193.

31 Phillips, P.C.B. and Durlauf, S.N. (1986) 'Multiply Time Series Regression with Integrated Processes', Review of Economic Studies, Vol. 53, pp. 473-496. 